\title{
Lipopolysaccharides upregulate calcium concentration in mouse uterine smooth muscle cells through the T-type calcium channels
}

\author{
LIJUAN ZHANG $^{1}$, LIN WANG ${ }^{2}$, JINGYI JIANG ${ }^{3}$, DONGMING ZHENG $^{1}$, SISHI LIU $^{1}$ and CAIXIA LIU ${ }^{1}$ \\ Departments of ${ }^{1}$ Obstetrics and Gynecology and ${ }^{2}$ Emergency Medicine, Shengjing Hospital of China Medical University, \\ Shenyang 110004; ${ }^{3}$ Clinical, Medical and Pharmaceutical College, China Medical University, Shenyang 110002, P.R. China
}

Received August 4, 2014; Accepted December 8, 2014

DOI: $10.3892 / \mathrm{ijmm} .2014 .2054$

\begin{abstract}
Infection is a significant cause of preterm birth. Abnormal changes in intracellular calcium signals are the ultimate triggers of early uterine contractions that result in preterm birth. T-type calcium channels play an important role in the pathogenesis of cancer, as well as endocrine and cardiovascular diseases. However, there are limited studies on their role in uterine contractions and parturition. In the present study, mouse uterine smooth muscle cells were isolated and treated with lipopolysaccharides (LPS) to mimic the microenvironment of uterine infection in vitro to investigate the role of T-type calcium channels in the process of infection-induced preterm birth. The results from quantitative polymerase chain reaction and western blot analysis showed that LPS significantly induced the expression of the Cav3.1 and Cav3.2 subtypes of T-type calcium channels. Measurements of intracellular calcium concentration showed a significant increase in response to LPS. However, these effects can be reversed by T-type calcium channel blockers. Western blot analysis further indicated that LPS induced the activation of the nuclear factor (NF)- $\kappa$ B signaling pathway, and endothelin-1 (ET-1) was significantly upregulated, whereas NF- $\mathrm{B}$ inhibitors significantly inhibited the LPS-induced upregulation of Cav3.1, Cav3.2 and ET-1 expression. In addition, ET-1 directly induced Cav3.1 and Cav3.2 expression, whereas ET-1 antagonists inhibited the LPS-induced upregulation of Cav3.1 and Cav3.2 expression. In conclusion, the present study demonstrates that infection triggers the upregulation of T-type calcium channels and promotes calcium influx. This process relies on the activation of the NF- $\mathrm{KB} / \mathrm{ET}-1$ signaling pathway. The T-type calcium channel is expected to become an effective target for the prevention of infection-induced preterm birth.
\end{abstract}

Correspondence to: Dr Caixia Liu, Department of Obstetrics and Gynecology, Shengjing Hospital of China Medical University, 36 Sanhao Street, Shenyang 110004, P.R. China

E-mail: cx1123wz@126.com

Key words: lipopolysaccharides, mouse uterine smooth muscle cells, T-type calcium channels, nuclear factor- $\kappa \mathrm{B}$, endothelin-1

\section{Introduction}

Preterm birth is an extremely common and problematic complication in perinatal medicine and is one of the leading causes of perinatal mortality $(1,2)$. Infants that survive preterm birth often suffer from health problems, including cerebral palsy, cognitive dysfunction, blindness, hearing loss and respiratory system damage $(3,4)$, which can place a significant responsibility on individuals and families. Clinical studies have shown that $40 \%$ of preterm births are caused by infection (5). Accumulating evidence indicates that infection is not only an important reason to induce preterm labor $(6,7)$ but also a potential target for the prevention of preterm birth (8). Therefore, it is important to further explore the pathogenesis of preterm birth caused by infection to reduce the risk of preterm birth and improve the perinatal survival rate.

One of the well-known main clinical manifestations of preterm birth is early contractions of the uterus, and the ultimate factor inducing uterine contraction is the changes of calcium signals in uterine smooth muscle cells (9-11). Voltage-gated calcium-channels (VGCCs) are heterologous multimeric transmembrane proteins located in the cell membrane and they are responsible for transporting extracellular calcium ions into the cells. VGCCs play an important role in the regulation of intracellular calcium signals. The VGCCs of uterine smooth muscles are mainly L- and T-type (12). Previous studies on the inducing factors of obstetric labor have mainly focused on L-type calcium channels. L-type calcium channel inhibitors, such as nifedipine, have been used as one of the first-line drugs in the treatment of premature delivery (13-15). The roles of T-type calcium channels are also extremely extensive, involving areas including tumor development (16-19), and endocrine (20-22) and cardiovascular diseases (23-26). However, there have been limited studies on their role in uterine contractions and labor induction.

In the present study, mouse uterine smooth muscle cells were isolated. Lipopolysaccharides (LPS) were used for cell treatment. Under infectious conditions, the expression of T-type calcium channels and the changes in calcium concentration of uterine smooth muscle cells were measured and the possible mechanisms were explored. The results showed that infection induced the upregulation of T-type calcium channel expression and further increased the concentration of calcium in uterine smooth muscle cells, in which the nuclear factor 


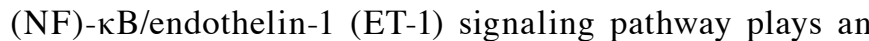
important role.

\section{Materials and methods}

Establishing the mouse model of pregnancy. Twelve-week-old female C57BL/6 mice weighing 22-25 g were purchased from the Animal Center laboratory of the China Medical University (Shenyang, China). The mice were fed and housed in a standard laboratory environment for a week for adaptation prior to the experiment. The maintenance and handling of experimental animals was approved by the Committee on Animal Research and Ethics of the China Medical University. On day 1, the mice were housed together with a female to male ratio of 2:1 in the cage. The vaginal plugs were checked on the morning of the day 2. When positive for a vaginal plug, the mouse was listed as in gestation day 0 . Pregnancy was confirmed on gestation days 7 and 12 . Healthy pregnant mice were selected for the experiments.

Isolation and culture of mouse uterine smooth muscle cells. Mouse uterine smooth muscle cells were isolated based on the methods used in previous studies $(27,28)$. The uterine tissues of pregnant mice were isolated under sterile conditions. Pre-chilled D-Han's solution (containing $100 \mathrm{U} / \mathrm{ml}$ of penicillin-streptomycin) was used to remove impurities. The serosa and endometrium were removed. The intermediate smooth muscle layers were cut into 2-3- $\mathrm{mm}^{3}$ sections. A digestive solution mixture of $0.25 \%$ trypsin (Beyotime Institute of Biotechnology, Haimen, China) and $0.25 \%$ type I collagenase (Invitrogen Life Technologies, Carlsbad, CA, USA) was added, and digestion proceeded at $37^{\circ} \mathrm{C}$ for $50 \mathrm{~min}$. Subsequently, $20 \%$ fetal bovine serum in Dulbecco's modified Eagle's medium (DMEM; Gibco Life Technologies, Grand Island, NY, USA) was added to terminate the reaction. The cells were filtered using 200-mesh filters. The supernatant was discarded following centrifugation. After washing with phosphate-buffered saline (PBS), $10 \%$ fetal bovine serum in DMEM was added to re-suspend the cells. The cells were subsequently seeded into 6-well plates and placed in the incubator. After $24 \mathrm{~h}$, the cell adherence was observed and the medium was changed. The medium was subsequently changed every 3 days. The cells from the third passage were selected to conduct the experiments. In the LPS group, 2,000 $\mathrm{ng} / \mathrm{ml}$ LPS was added to treat the cells for $12 \mathrm{~h}$, whereas in the saline group, an equal volume of saline was added. The untreated uterine smooth muscle cells were used as a control group. In the NF- $\mathrm{KB}$ inhibitor group, $100 \mu \mathrm{M}$ BAY 11-7028 (Beyotime Institute of Biotechnology) was added prior to treatment with LPS. In the ET-1 treatment group, 50 nM ET-1 (Sigma-Aldrich, St. Louis, MO, USA) was added. In the ET-1 antagonist group, $10 \mu \mathrm{M}$ bosentan (Santa Cruz Biotechnology, Inc., Santa Cruz, CA, USA) was added.

Immunofluorescence. The third passage of uterine smooth muscle cells were seeded in 6-well plates with cover slips. After the cells became $~ 100 \%$ confluent, $4 \%$ paraformaldehyde was applied to fix the cells for $15 \mathrm{~min}$. Once the fixative was discarded, $0.1 \%$ Triton X-100 was added until all the cells were covered. The cells were incubated for $30 \mathrm{~min}$ at room temperature. Subsequent to blocking the cells with goat serum, $\alpha$-smooth muscle actin (SMA) antibody (ab40863) with 1:100 dilution (Abcam, Cambridge, MA, USA) was added, and the cells were incubated overnight at $4^{\circ} \mathrm{C}$. The cells were washed and fluorescein isothiocyanate-labeled secondary antibody (A0562; Beyotime Institute of Biotechnology) with 1:200 dilution was added, after which the cells were incubated at room temperature for $60 \mathrm{~min}$. 4',6-Diamidino-2-phenylindole (DAPI) was added for nuclear staining. The fluorescence quencher was added dropwise, and the slices were mounted. Images were obtained using a laser scanning confocal microscope (FV1000S-SIM/IX81; Olympus, Tokyo, Japan).

Quantitative polymerase chain reaction ( $q P C R$ ). TRIzol reagent (Invitrogen Life Technologies) was used to extract the total RNA of the cells in each group. The RNA was reverse transcribed to cDNA using a cDNA first strand synthesis kit (Takara Bio, Inc., Dalian, China), according to the manufacturer's instructions. The upstream and downstream primer sequences of Cav3.1 are 5'-ATAACAGTTCCAGCAATACCACC-3' and 5'-GAATGAGCATCCATCACAAAGT-3', respectively, The length of the amplified fragment was 190 base pairs (bp). The upstream and downstream primer sequences of Cav3.2 are 5'-AGAGCCGTTGGCGTAAGAAG-3' and 5'-GCTGAAGTGGTAATGGTGGTGA-3', respectively. The length of the amplified fragment was $152 \mathrm{bp}$. The upstream and downstream primer sequences of $\beta$-actin are 5'-CTGTGCCCATCTACGAGGGCTAT-3' and 5'-TTTGAT GTCACGCACGATTTCC-3', respectively. The length of the amplified fragment was 155 bp. qPCR was conducted using an Exicycler ${ }^{\mathrm{TM}} 96$ Quantitative fluorescence Real-Time PCR System (Bioneer, Daejeon, Korea). The reaction volume was $20 \mu \mathrm{l}$, including $1 \mu \mathrm{l} \mathrm{cDNA}, 0.5 \mu \mathrm{l}$ of each upstream and downstream primer, $10 \mu 1$ SYBR GREEN mastermix and $8 \mu 1 \mathrm{ddH}_{2} \mathrm{O}$. The PCR reaction program was $95^{\circ} \mathrm{C}$ for $10 \mathrm{~min}$ followed by 40 cycles of $95^{\circ} \mathrm{C}$ for $10 \mathrm{sec}, 58^{\circ} \mathrm{C}$ for $20 \mathrm{sec}$ and $72^{\circ} \mathrm{C}$ for $30 \mathrm{sec}$; and subsequently $4^{\circ} \mathrm{C}$ for $5 \mathrm{~min}$.

Western blot analysis. Radioimmunoprecipitation assay lysis buffer (Beyotime Institute of Biotechnology) was used for cell lysis. The bicinchoninic acid method was used for protein quantification and balancing. A total of $40 \mu \mathrm{g}$ protein from each group was used for SDS-PAGE. The sample was electronically transferred to a PVDF membrane (Millipore, Bedford, MA, USA) following electrophoresis. After 5\% skimmed milk powder was added at room temperature and blocked for $1 \mathrm{~h}$, diluted primary antibody [Cav3.1 (sc-28617) and Cav3.2 (sc-25691), 1:200 dilution; Santa Cruz Biotechnology, Inc.; NF-кB p65 (WL00666), p-IкB (WL00020) and ET-1 (WL00138), 1:400 dilution; 1:400 dilution; Wanleibio, Shenyang, China] was added at $4^{\circ} \mathrm{C}$ and incubated overnight. Subsequently, 1:5,000 diluted horseradish peroxidase-labeled secondary antibody (A0208; Beyotime Institute of Biotechnology) was added and incubated at $37^{\circ} \mathrm{C}$ for $1 \mathrm{~h}$. An electrochemiluminescence method was used for substrate luminescence. Following exposure, the images were scanned into the computer and grayscale analysis was performed by Image $\mathbf{J}$ software (Image J Version 1.36b; National Institutes of Health, Bethesda, MD, USA); $\beta$-actin was used as an internal reference to analyze the expression level of each protein.

Detection of intracellular calcium ion concentration. The concentration of intracellular calcium ions was measured using 

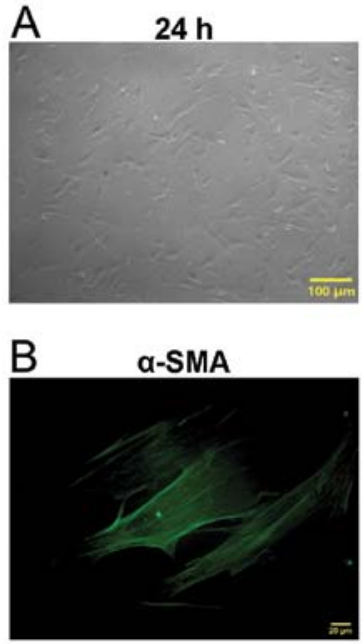

$48 \mathrm{~h}$

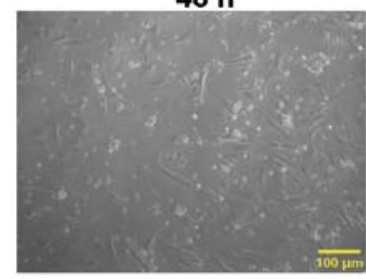

DAPI

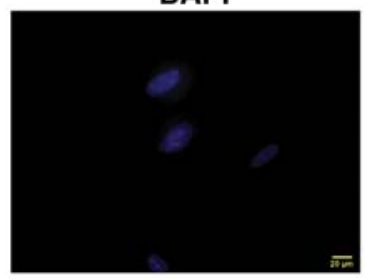

Day 7

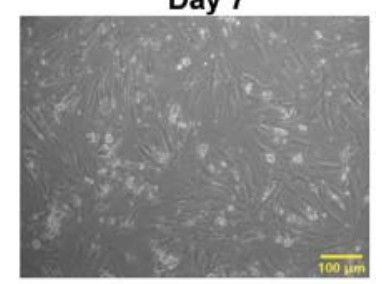

MERGE

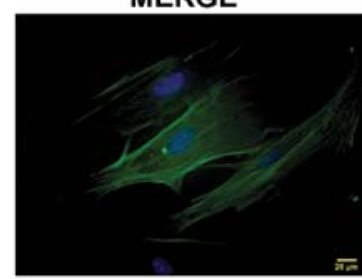

Figure 1. Culture and identification of mouse uterine smooth muscle cells. (A) A trypsin-collagenase I mixed enzyme digestion method was used to isolate uterine smooth muscle cells from pregnant mice. The cell morphology was observed under inverted microscope $24,48 \mathrm{~h}$ and 7 days after inoculation. (B) Immunofluorescence detection of $\alpha$-SMA expression in mouse uterine smooth muscle cells. Green filamentous $\alpha$-SMA protein and DAPI stained blue nuclei can be observed within the cells. The representative results are shown in the figure. $\alpha$-SMA, $\alpha$-smooth muscle actin; DAPI, 4',6-diamidino-2-phenylindole.

the method of Wang et al (29). In the T-type calcium channel inhibitor group, $5 \mu \mathrm{M}$ NNC 55-0396 was added $10 \mathrm{~min}$ before LPS treatment started (30). After the cells in each group were collected and washed twice with PBS, $1 \mathrm{ml} 5 \mu \mathrm{M}$ serum-free Fluo-3AM was added and incubated at $37^{\circ} \mathrm{C}$ in the dark for $30 \mathrm{~min}$. The cells were washed three times and continued to incubate for another $20 \mathrm{~min}$ to allow the complete conversion of Fluo-3AM to Fluo-3. Cells were collected and analyzed by a flow cytometer (BD Biosciences, San Jose, CA, USA).

Statistical analysis. The experimental data are presented as the means \pm standard deviation. One-way analysis of variance was used for comparison between the groups. The Bonferroni post-hoc test was used for multiple comparisons. GraphPad Prism 5.0 software (Graph Pad, San Diego, CA, USA) was used for data processing. A value of $\mathrm{P}<0.05$ was considered to represent a statistically significant difference.

\section{Results}

Isolation, culture and identification of mouse uterine smooth muscle cells. The uterine tissues of pregnant mice were obtained. Uterine smooth muscle cells were isolated using the trypsin-collagenase I mixed enzyme digestion method (Fig. 1A). After $24 \mathrm{~h}$, the cells had already adhered to the wall of the wells and presented as fusiform or polygonal shapes. The cell clones were visible after $48 \mathrm{~h}$. Cells were fused into pieces after 7 days. The cells from the third passage were collected for $\alpha$-SMA immunofluorescence staining (Fig. 1B). The results showed green filamentous actin in the cytoplasm, while the nuclei were stained blue with DAPI indicating that mouse uterine smooth muscle cells had been isolated.

LPS induces upregulation of T-type calcium channel subtypes, Cav3.1 and Cav3.2, in mouse uterine smooth muscle cells. Bacterial endotoxin LPS were used to treat uterine smooth muscle cells to mimic an infectious uterine microenvironment in vitro (31) to investigate the effect of infection on T-type calcium channels (Fig. 2). The results showed that after $6 \mathrm{~h}$ of LPS treatment, there was a significant increase in Cav3.1 and Cav3.2 mRNA $(\mathrm{P}<0.01)$, and the expression increased with the increasing duration of LPS treatment. Western blot analysis of the two proteins showed similar results to the mRNA expression; LPS significantly increased the expression of Cav3.1 and Cav3.2 $(\mathrm{P}<0.01)$. Therefore, infection can cause the upregulation of T-type calcium channel expression.

LPS upregulate calcium concentration through T-type calcium channels in uterine smooth muscle cells. Increasing the intracellular calcium concentration can directly cause uterine contractions (32). Therefore, the intracellular calcium concentration of uterine smooth muscle cells was examined to investigate the role of infection and T-type calcium channels in uterine contractions (Fig. 3). The results showed that following LPS treatment, the intracellular calcium concentration increased $>3$-fold $(\mathrm{P}<0.01)$. However, subsequent to applying the T-type calcium channel inhibitors, the calcium concentration was significantly reduced $(\mathrm{P}<0.01)$. As the LPS-induced increases in calcium concentration can be reversed, this indicates that the infection can lead to calcium influx in uterine smooth muscle cells. In this process, T-type calcium channels play an essential role.

LPS upregulates the expression of T-type calcium channels via the $N F-\kappa B$ signaling pathway. The activation of the $N F-\kappa B$ signaling pathway was determined to investigate the mechanism of T-type calcium channel upregulation by LPS (Fig. 4). The results showed that compared to the control group, the expression of $\mathrm{p}-\mathrm{I} \kappa \mathrm{B}$ in the cytoplasm and $\mathrm{NF}-\kappa \mathrm{B}$ p65 in the nucleus was significantly higher in the LPS treatment group $(\mathrm{P}<0.01)$, indicating that LPS can activate the NF- $\kappa \mathrm{B}$ signaling pathway of mouse uterine smooth muscle cells. Subsequent to applying the $\mathrm{NF}-\kappa \mathrm{B}$ inhibitors, the LPS-induced upregulation of Cav3.1 and Cav3.2 was significantly reversed $(\mathrm{P}<0.01)$. Therefore, $N F-\kappa B$ played a role in the LPS-induced upregulation of T-type calcium channel expression. 


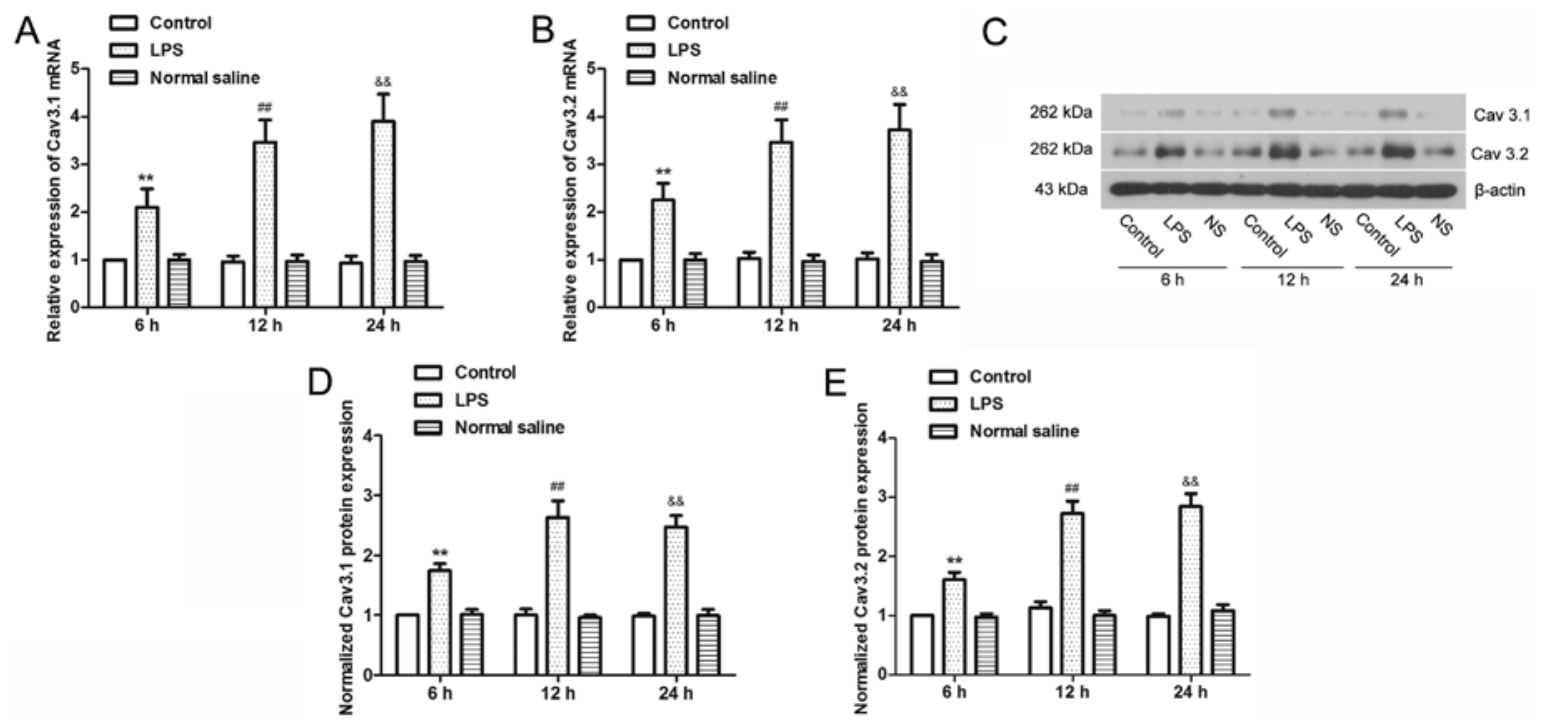

Figure 2. LPS can upregulate the expression of Cav3.1 and Cav3.2 in smooth muscle cells in the uterus. qPCR measured the mRNA expression of (A) Cav3.1 and (B) Cav3.2. (C) Western blot analysis was used to measure the expression of Cav3.1 and Cav3.2 proteins. Typical results from repeated experiments are shown in the figure with $\beta$-actin as an internal reference for the analysis of (D) Cav3.1 and (E) Cav3.2 protein levels; $\mathrm{n}=3$. The data are expressed as the means \pm standard deviation. ${ }^{* *} \mathrm{P}<0.01$ compared to the control group at $6 \mathrm{~h} ;{ }^{\# \#} \mathrm{P}<0.01$ compared to the control group at $12 \mathrm{~h}$; and \&\& $\mathrm{P}<0.01$ compared to the control group at $24 \mathrm{~h}$. LPS, lipopolysaccharides; qPCR, quantitative polymerase chain reaction; NS, normal saline.
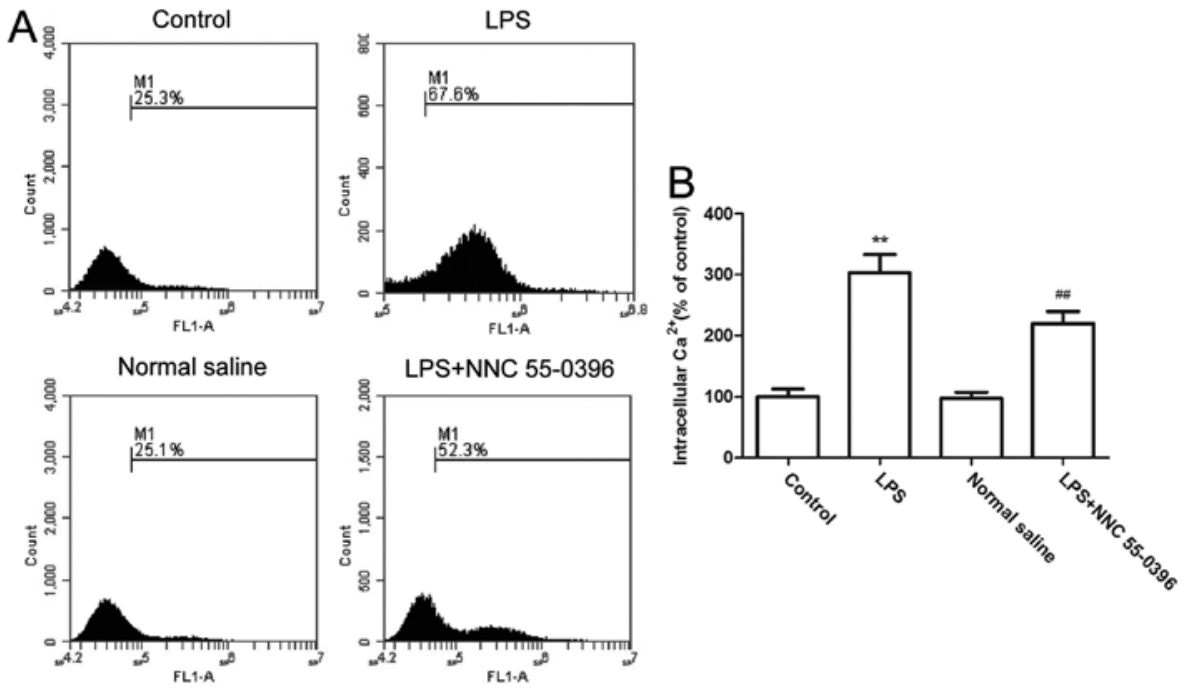

Figure 3. LPS increase calcium concentration in uterine smooth muscle cells. (A) Fluo-3AM tests were used to measure the calcium concentrations in cells of each group. Representative results from repeated experiments of each group are shown in the figure. (B) Relative calcium levels of cells in each group; $n=3$. The data are expressed as the means \pm standard deviation. ${ }^{* *} \mathrm{P}<0.01$ compared to the control group; and ${ }^{\# /} \mathrm{P}<0.01$ compared to the LPS group. LPS, lipopolysaccharides.

ET-1-mediated NF- $\kappa B$ signaling is involved in the regulation of T-type calcium channels by LPS. ET-1 is an important factor that can induce calcium influx, as well as induce cell contraction $(33,34)$. Therefore, the expression of ET-1 was measured to investigate whether it was involved in the regulation of T-type calcium channels by LPS (Fig. 5). The results showed that the expression of ET-1 was significantly increased subsequent to treatment with LPS $(\mathrm{P}<0.01)$, indicating that LPS can induce the expression of ET-1 in uterine smooth muscle cells. Further experiments showed that NF- $\mathrm{KB}$ inhibitors reduced the LPS-induced upregulation of ET-1 expression (Fig. 5C and D). Therefore, ET-1 was regulated by NF- $\mathrm{kB}$. Subsequent to direct treatment of the uterine smooth muscle cells with ET-1, the expression of Cav3.1 and Cav3.2 was upregulated, while the ET-1 antagonist, bosentan, reversed the effect of LPS on the above two factors (Fig. 5E and F). These results indicate that ET-1 mediates NF- $\mathrm{KB}$ signaling and participates in the regulation of T-type calcium channels by LPS.

\section{Discussion}

In the present study, mouse uterine smooth muscle cells were isolated. LPS were applied to treat the cells to mimic the microenvironment of uterine infection in vitro. The mechanisms through which an infection affects the T-type calcium channels and intracellular calcium concentration were also explored. The results indicated that LPS significantly upregulated the expression of T-type calcium channel subtypes 

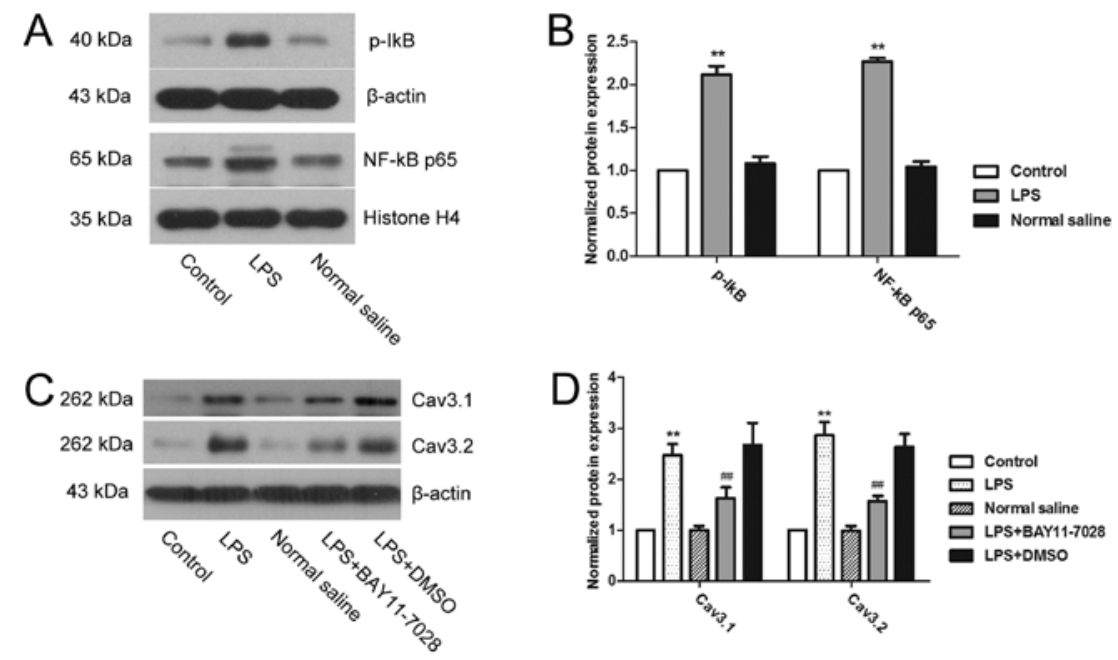

Figure 4. LPS increase Cav3.1 and Cav3.2 expression via the NF- $\mathrm{kB}$ signaling pathway. Western blot analysis was used to detect the expression of (A) p-IкB in

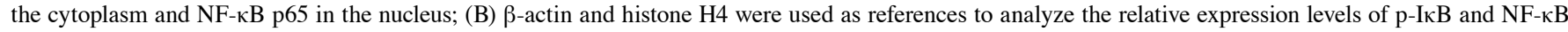
p65; respectively. (C) Western blotting detected the expression of Cav3.1 and Cav3.2; and (D) $\beta$-actin was used as an internal reference for the analysis of relative Cav3.1 and Cav3.2 expression levels. The western blot results in the figure are typical results from three repeated experiments, and the data are expressed as the means \pm standard deviation. ${ }^{* *} \mathrm{P}<0.01$ compared to the control group; and ${ }^{\# \#} \mathrm{P}<0.01$ compared to the LPS group. LPS, lipopolysaccharides; NF- $\kappa B$, nuclear factor- $\kappa \mathrm{B}$.

A

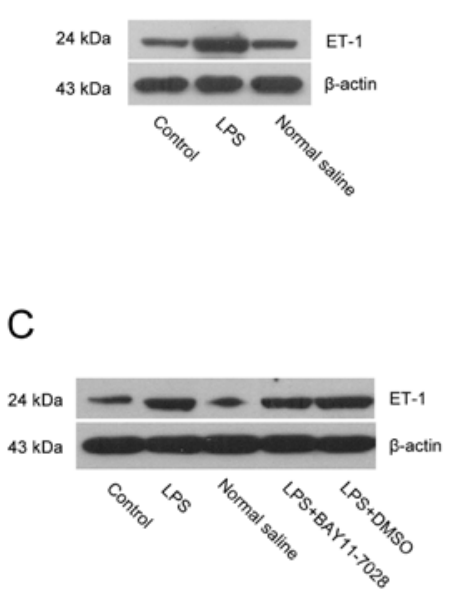

E

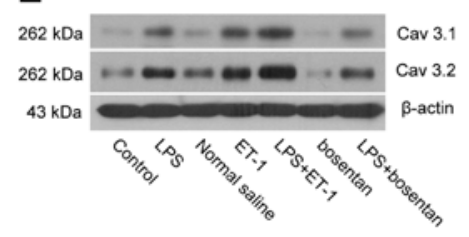

B
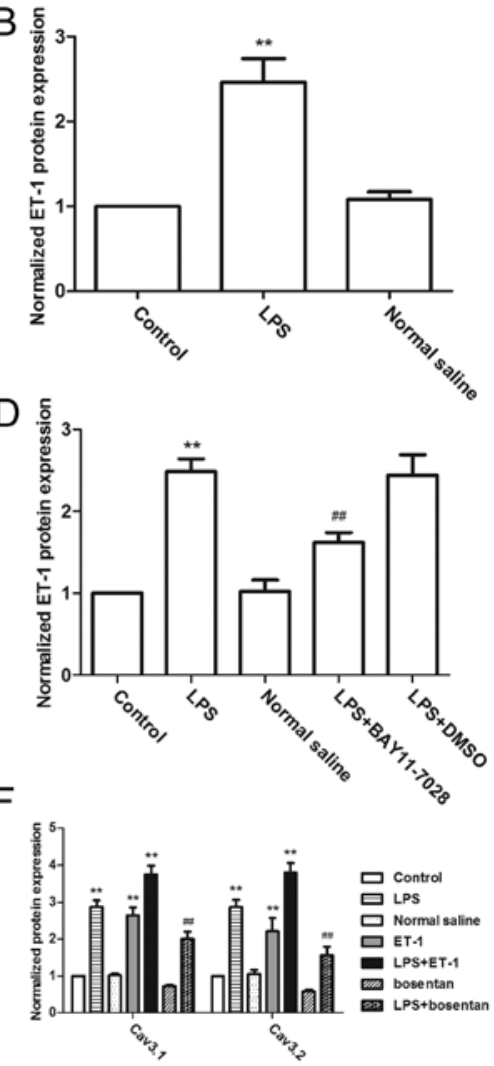

Figure 5. ET-1-mediated NF-kB signaling in LPS regulation of T-type calcium channels. Western blot analysis was used to detect the expression of (A, C) ET-1 and (E) Cav3.1 and Cav3.2; (B, D, F) $\beta$-actin was used as an internal reference for analysis of the relative expression level of each protein. The western blot results are typical results from three repeated experiments for each group. The data are expressed as the means \pm standard deviation. ${ }^{* *} \mathrm{P}<0.01$ compared to the control group; and ${ }^{\# \#} \mathrm{P}<0.01$ compared to the LPS group. ET-1, endothelin-1; NF- $\kappa$ B, nuclear factor- $\kappa$ B; LPS, lipopolysaccharides;

Cav3.1 and Cav3.2 and increased the concentration of calcium in the uterine smooth muscle cells. This process depends on the activation of the NF- $\mathrm{KB} / \mathrm{ET}-1$ signaling pathways. The above results show that T-type calcium channels play an important role in infection-induced calcium influx. T-type calcium channels are expected to become a novel target for the prevention of preterm birth.

In the signal transduction process during uterine smooth muscle cell contraction in pregnant females, the ultimate step controlling contraction is the changes in cytosolic 
calcium signaling (32). T-type calcium channels are a class of low activation potential, small single-channel conductance voltage-gated calcium channels that can directly regulate intracellular calcium ion concentrations. T-type calcium channels also play a role as a secondary messenger in a variety of physiological and pathological processes $(23,35-37)$. T-type calcium channels expressed in uterine smooth muscle cells are mainly Cav3.1 and Cav3.2 subtypes (38). LPS is the main toxic component of Gram-negative bacteria (39). Levels of LPS were increased in the amniotic cavity of premature patients with bacterial infection (40). In the present study, the use of LPS for the treatment of uterine smooth muscle cells to mimic an in vitro bacterial infection microenvironment found that the expression of Cav3.1 and Cav3.2 was significantly upregulated in the infectious condition, and the intracellular calcium concentration also increased. However, T-type calcium channel antagonists can effectively inhibit the infection-induced increase of calcium concentration, indicating that T-type calcium channels play an indispensable role in the LPS signal transmission and the regulation of intracellular calcium concentration processes. Increased calcium concentration by excitable cells is known to lead to cell shrinkage (41). T-type calcium channels in the infectious condition are speculated to trigger uterine contractions, while T-type calcium channel antagonist agents can prevent preterm birth caused by infection.

$\mathrm{NF}-\kappa \mathrm{B}$ is an important transcription factor. Activation can cause uterine smooth muscle cells to produce a variety of inflammatory cytokines and active substances, promoting intracellular calcium influx and inducing uterine contractions that lead to preterm birth (42). In the present study, under the treatment of LPS, there was a significant increase in the expression of cytosolic $\mathrm{p}-\mathrm{I} \kappa \mathrm{B}$ and $\mathrm{NF}-\kappa \mathrm{B}$ p65 in the nucleus, suggesting that infection conditions can activate the NF- $\kappa \mathrm{B}$ signaling pathway, which has been confirmed in numerous previous studies $(43,44)$. NF- $\kappa \mathrm{B}$ antagonists were further demonstrated to reverse the LPS-induced increase in Cav3.1 and Cav3.2 expression. Therefore, the increased expression of T-type calcium channels by infection partially depends on the activation of the NF- $\kappa \mathrm{B}$ signaling pathway.

ET-1 is one of the small proteins with strong vasoconstriction activities $(45,46)$. Under stimulation, the uterus can produce ET-1 and release it in the paracrine form to induce contraction (47). The process of ET-1-induced uterine contractions ultimately depends on the increase in intracellular calcium concentration (48). In the present study, it was found that following LPS treatment the expression of ET-1 was elevated, whereas NF- $\kappa \mathrm{B}$ inhibitors reversed the effect of LPS on ET-1. Therefore, infection induces the release of ET-1 through the NF- $\kappa \mathrm{B}$ signaling pathway, which is consistent with previous studies $(49,50)$. The present study also found that ET-1 can directly increase the expression of Cav3.1 and Cav3.2. In addition, ET-1 antagonists inhibited the LPS-induced upregulation of Cav3.1 and Cav3.2, indicating an important role of ET-1 in the upregulation of T-type calcium channels and calcium influx in uterine smooth muscle cells. Similar results have also been demonstrated in myocardial cells $(51,52)$.

In conclusion, the results demonstrated that infection can induce the upregulation of T-type calcium channels and facilitate calcium influx in uterine smooth muscle cells. This process is closely associated with the activation of the NF- $\mathrm{B} / \mathrm{ET}-1$ signaling pathway. The study illustrated the role of T-type calcium channels in premature birth caused by infection. T-type calcium channels are expected to become a novel target for the prevention of infection-induced preterm birth.

\section{Reference}

1. Goldenberg RL, Hauth JC and Andrews WW: Intrauterine infection and preterm delivery. N Engl J Med 342: 1500-1507, 2000.

2. Lawn JE, Cousens S and Zupan J; Lancet Neonatal Survival Steering Team: 4 million neonatal deaths: when? where? why? Lancet 365: 891-900, 2005.

3. Trachtenbarg DE and Golemon TB: Care of the premature infant: Part I. Monitoring growth and development. Am Fam Physician 57: 2123-2130, 1998.

4. Howson CP, Kinney MV, McDougall L and Lawn JE; Born Too Soon Preterm Birth Action Group: Born too soon: preterm birth matters. Reprod Health 10 Suppl 1: S1, 2013.

5. Lamont RF: Infection in the prediction and antibiotics in the prevention of spontaneous preterm labour and preterm birth. BJOG 110 Suppl 20: 71-75, 2003.

6. Shim SS, Romero R, Hong JS, et al: Clinical significance of intra-amniotic inflammation in patients with preterm premature rupture of membranes. Am J Obstet Gynecol 191: 1339-1345, 2004.

7. Christiaens I, Zaragoza DB, Guilbert L, Robertson SA, Mitchell BF and Olson DM: Inflammatory processes in preterm and term parturition. J Reprod Immunol 79: 50-57, 2008.

8. Shynlova O, Dorogin A, Li Y and Lye S: Inhibition of infection-mediated preterm birth by administration of broad spectrum chemokine inhibitor in mice. J Cell Mol Med 18: 1816-1829, 2014.

9. Shmygol A and Wray S: Modulation of agonist-induced $\mathrm{Ca}^{2+}$ release by $\mathrm{SR} \mathrm{Ca}^{2+}$ load: direct $\mathrm{SR}$ and cytosolic $\mathrm{Ca}^{2+}$ measurements in rat uterine myocytes. Cell Calcium 37: 215-223, 2005.

10. Floyd R and Wray S: Calcium transporters and signalling in smooth muscles. Cell Calcium 42: 467-476, 2007.

11. Young RC: Myocytes, myometrium, and uterine contractions. Ann N Y Acad Sci 1101: 72-84, 2007.

12. Kamkin AG, Kiseleva IS, Kirishchuk SI and Lozinskiǔ IT: Voltage-gated calcium channels. Usp Fiziol Nauk 37: 3-33, 2006 (In Russian).

13. Flenady V, Wojcieszek AM, Papatsonis DN, et al: Calcium channel blockers for inhibiting preterm labour and birth. Cochrane Database Syst Rev 6: CD002255, 2014.

14. King JF, Flenady VJ, Papatsonis DN, Dekker GA and Carbonne B: Calcium channel blockers for inhibiting preterm labour. Cochrane Database Syst Rev CD002255, 2003.

15. Tranquilli AL and Giannubilo SR: Use and safety of calcium channel blockers in obstetrics. Curr Med Chem 16: 3330-3340, 2009.

16. Jang SJ, Choi HW, Choi DL, et al: In vitro cytotoxicity on human ovarian cancer cells by T-type calcium channel blockers. Bioorg Med Chem Lett 23: 6656-6662, 2013.

17. Santoni G, Santoni M and Nabissi M: Functional role of T-type calcium channels in tumour growth and progression: prospective in cancer therapy. Br J Pharmacol 166: 1244-1246, 2012.

18. Choi DL, Jang SJ, Cho S, et al: Inhibition of cellular proliferation and induction of apoptosis in human lung adenocarcinoma A549 cells by T-type calcium channel antagonist. Bioorg Med Chem Lett 24: 1565-1570, 2014.

19. Ohkubo T and Yamazaki J: T-type voltage-activated calcium channel Cav3.1, but not Cav3.2, is involved in the inhibition of proliferation and apoptosis in MCF-7 human breast cancer cells. Int J Oncol 41: 267-275, 2012.

20. Bhattacharjee A, Whitehurst RM Jr, Zhang M, Wang L and Li M: T-type calcium channels facilitate insulin secretion by enhancing general excitability in the insulin-secreting beta-cell line, INS-1. Endocrinology 138: 3735-3740, 1997.

21. Scholze A, Plant TD, Dolphin AC and Nürnberg B: Functional expression and characterization of a voltage-gated CaV1.3 (alpha1D) calcium channel subunit from an insulin-secreting cell line. Mol Endocrinol 15: 1211-1221, 2001 
22. Young RC and Zhang P: Inhibition of in vitro contractions of human myometrium by mibefradil, a T-type calcium channel blocker: support for a model using excitation-contraction coupling, and autocrine and paracrine signaling mechanisms. J Soc Gynecol Investig 12: e7-e12, 2005.

23. Lalevée N, Rebsamen MC, Barrère-Lemaire S, et al: Aldosterone increases T-type calcium channel expression and in vitro beating frequency in neonatal rat cardiomyocytes. Cardiovasc Res 67: 216-224, 2005.

24. Cribbs LL: T-type $\mathrm{Ca}^{2+}$ channels in vascular smooth muscle: multiple functions. Cell Calcium 40: 221-230, 2006.

25. Pluteanu F and Cribbs LL: Regulation and function of Cav3.1 T-type calcium channels in IGF-i-stimulated pulmonary artery smooth muscle cells. Am J Physiol Cell Physiol 300: C517-C525, 2011.

26. Tzeng BH, Chen $\mathrm{YH}$, Huang $\mathrm{CH}$, Lin SS, Lee KR and Chen CC: The $\mathrm{Ca}(\mathrm{v}) 3.1 \mathrm{~T}$-type calcium channel is required for neointimal formation in response to vascular injury in mice. Cardiovasc Res 96: 533-542, 2012.

27. Oldenhof AD, Shynlova OP, Liu M, Langille BL and Lye SJ: Mitogen-activated protein kinases mediate stretch-induced c-fos mRNA expression in myometrial smooth muscle cells. Am J Physiol Cell Physiol 283: C1530-C1539, 2002.

28. Mitchell JA, Shynlova O, Langille BL and Lye SJ: Mechanical stretch and progesterone differentially regulate activator protein-1 transcription factors in primary rat myometrial smooth muscle cells. Am J Physiol Endocrinol Metab 287: E439-E445, 2004.

29. Wang M, Ruan Y, Chen Q, Li S, Wang Q and Cai J: Curcumin induced HepG2 cell apoptosis-associated mitochondrial membrane potential and intracellular free $\mathrm{Ca}(2+)$ concentration. Eur J Pharmacol 650: 41-47, 2011.

30. Okubo K, Takahashi T, Sekiguchi F, et al: Inhibition of T-type calcium channels and hydrogen sulfide-forming enzyme reverses paclitaxel-evoked neuropathic hyperalgesia in rats. Neuroscience 188: 148-156, 2011.

31. Thota C, Farmer T, Garfield RE, Menon R and Al-Hendy A: Vitamin $D$ elicits anti-inflammatory response, inhibits contractile-associated proteins, and modulates toll-like receptors in human myometrial cells. Reprod Sci 20: 463-475, 2013.

32. Wray S, Jones $\mathrm{K}$, Kupittayanant $\mathrm{S}$, et al: Calcium signaling and uterine contractility. J Soc Gynecol Investig 10: 252-264, 2003.

33. Bouallegue A,Daou GB and Srivastava AK: Endothelin-1-induced signaling pathways in vascular smooth muscle cells. Curr Vasc Pharmacol 5: 45-52, 2007.

34. Masamune A, Satoh M, Kikuta K, Suzuki N and Shimosegawa T: Endothelin-1 stimulates contraction and migration of rat pancreatic stellate cells. World J Gastroenterol 11: 6144-6151, 2005.

35. Chemin J, Monteil A, Perez-Reyes E, Bourinet E, Nargeot J and Lory P: Specific contribution of human T-type calcium channel isotypes (alpha $(1 \mathrm{G})$, alpha $(1 \mathrm{H})$ and alpha(1I)) to neuronal excitability. J Physiol 540: 3-14, 2002.

36. Yu W, Wang P, Ma H, et al: Suppression of T-type $\mathrm{Ca}^{2+}$ channels inhibited human laryngeal squamous cell carcinoma cell proliferation running title: roles of T-type $\mathrm{Ca}^{2+}$ channels in LSCC cell proliferation. Clin Lab 60: 621-628, 2014.
37. Chen Y, Parker WD and Wang K: The role of T-type calcium channel genes in absence seizures. Front Neurol 5: 45, 2014.

38. Cens T, Rousset M, Kajava A and Charnet P: Molecular determinant for specific ca/ba selectivity profiles of low and high threshold $\mathrm{Ca}^{2+}$ channels. J Gen Physiol 130: 415-425, 2007.

39. Sperandeo P, Deho G and Polissi A: The lipopolysaccharide transport system of gram-negative bacteria. Biochim Biophys Acta 1791: 594-602, 2009.

40. Romero R, Espinoza J, Goncalves LF, Kusanovic JP, Friel LA and Nien JK: Inflammation in preterm and term labour and delivery. Semin Fetal Neonatal Med 11: 317-326, 2006.

41. Karaki H, Ozaki H, Hori M, et al: Calcium movements, distribution, and functions in smooth muscle. Pharmacol Rev 49: 157-230, 1997.

42. Hua R, Pease JE, Sooranna SR, et al: Stretch and inflammatory cytokines drive myometrial chemokine expression via NF- $\kappa \mathrm{B}$ activation. Endocrinology 153: 481-491, 2012.

43. Ikebe M, Kitaura Y, Nakamura M, et al: Lipopolysaccharide (IPS) increases the invasive ability of pancreatic cancer cells through the TLR4/MyD88 signaling pathway. J Surg Oncol 100: 725-731, 2009

44. Yamamoto Y and Gaynor RB: Role of the NF-kappaB pathway in the pathogenesis of human disease states. Curr Mol Med 1: 287-296, 2001.

45. Mitchell MD, Branch DW, Lamarche S and Dudley DJ: The regulation of endothelin production in human umbilical vein endothelial cells: unique inhibitory action of calcium ionophores. J Clin Endocrinol Metab 75: 665-668, 1992.

46. Wolff K, Nisell H, Modin A, Lundberg JM, Lunell NO and Lindblom B: Contractile effects of endothelin 1 and endothelin 3 on myometrium and small intramyometrial arteries of pregnant women at term. Gynecol Obstet Invest 36: 166-171, 1993.

47. Rae GA, Calixto JB and D'Orléans-Juste P: Effects and mechanisms of action of endothelins on non-vascular smooth muscle of the respiratory, gastrointestinal and urogenital tracts. Regul Pept 55: 1-46, 1995.

48. Robin P, Boulven I, Desmyter C, Harbon S and Leiber D: ET-1 stimulates ERK signaling pathway through sequential activation of PKC and src in rat myometrial cells. Am J Physiol Cell Physiol 283: C251-C260, 2002.

49. Ohkita M, Takaoka M, Shiota Y, Nojiri R, Sugii M and Matsumura Y: A nuclear factor-kappaB inhibitor BAY 11-7082 suppresses endothelin-1 production in cultured vascular endothelial cells. Jpn J Pharmacol 89: 81-84, 2002.

50. Sugii M, Ohkita M, Taniguchi M, et al: Xanthoangelol D isolated from the roots of Angelica keiskei inhibits endothelin-1 production through the suppression of nuclear factor-kappaB. Biol Pharm Bull 28: 607-610, 2005.

51. Furukawa T, Ito H, Nitta J, et al: Endothelin-1 enhances calcium entry through T-type calcium channels in cultured neonatal rat ventricular myocytes. Circ Res 71: 1242-1253, 1992.

52. Izumi T, Kihara Y, Sarai N, et al: Reinduction of T-type calcium channels by endothelin-1 in failing hearts in vivo and in adult rat ventricular myocytes in vitro. Circulation 108: 2530-2535, 2003. 